\title{
Association among fraction of exhaled nitrous oxide, bronchodilator response and inhaled corticosteroid type
}

\author{
Ryan W Smith BASc MSc MB BCh BAO ${ }^{1}$, Kim Downey RRT CAE ${ }^{2}$, Nadia Snow RRT CAE 2 , \\ Sharon Dell BEng MD FRCPC ${ }^{3}$, W Gary Smith MD FRCPC FAAP MHSc CHE ${ }^{2}$
}

\begin{abstract}
RW Smith, K Downey, N Snow, S Dell, WG Smith. Association among fraction of exhaled nitrous oxide, bronchodilator response and inhaled corticosteroid type. Can Respir J 2015;22(3):153-156.
\end{abstract}

BACKGROUND: Fraction of exhaled nitrous oxide (FeNO) is a known marker of airway inflammation and a topic of recent investigation for asthma control in children.

OBJECTIVE: To investigate the relationship among FeNO and bronchodilator response measured by spirometry and types of inhaled corticosteroids (ICS).

METHODS: A one-year review of children tested with spirometry and $\mathrm{FeNO}$ in a regional pediatric asthma centre was conducted.

RESULTS: A total of 183 children were included (mean $[ \pm$ SD] age $12.8 \pm 2.8$ years). Fluticasone was used most commonly $(n=66[36.1 \%])$, followed by ciclesonide $(n=50[27.3 \%])$. Most children $(n=73[39.9 \%])$ had moderate persistent asthma. Increased $\mathrm{FeNO}$ was associated with percent change in forced expiratory volume in $1 \mathrm{~s}\left(\mathrm{FEV}_{1}\right)$ after bronchodilator adjusted for allergic rhinitis, parental smoking and ICS type (B=0.08 [95\% CI 0.04 to 0.12]; $\mathrm{P}<0.001)$. Similarly, FeNO was associated with percent change in forced expiratory flow at $25 \%$ to $75 \%$ of the pulmonary volume $\left(\mathrm{FEF}_{25-75}\right)$ after bronchodilator adjusted for parental smoking and ICS type ( $\mathrm{B}=0.13$ [95\% CI 0.01 to 0.24 ]; $\mathrm{P}=0.03$ ). FeNO accounted for only $16 \%$ and $9 \%$ of the variability in $\mathrm{FEV}_{1}$ and $\mathrm{FEF}_{25-75}$, respectively. Meanadjusted FeNO was lowest in fluticasone users compared with no ICS (mean difference 18.6 parts per billion [ppb] [95\% CI 1.0 to 36.2]) and there was no difference in adjusted $\mathrm{FeNO}$ level between ciclesonide and no ICS (5.9 ppb [95\% CI -9.0 to 20.8]).

CONCLUSION: FeNO levels correlated with bronchodilator response in a regional pediatric asthma centre. However, FeNO accounted for only $16 \%$ and $9 \%$ of the variability in $\mathrm{FEV}_{1}$ and $\mathrm{FEF}_{25-75}$, respectively. Mean adjusted FeNO varied according to ICS type, suggesting a difference in relative efficacy between ICS beyond their dose equivalents.

Key Words: Asthma; Children; Exhaled airway markers; Fraction of exhaled nitrous oxide (FeNO); Inhaled corticosteroid (ICS)

$A$ sthma is defined as an inflammatory disease of the airways charAacterized by recurrent symptoms, reversible bronchoconstriction and obstruction of airway flow (1). Asthma is not uncommon, affecting approximately $8 \%$ to $15 \%$ of children in Canada (2). The mainstay of asthma management is the routine measurement of lung function with spirometry, including a measured response to bronchodilator. Spirometry is used initially to confirm the diagnosis of asthma and, subsequently, to monitor asthma control (3). On spirometry testing, the ratio of forced expiratory volume in $1 \mathrm{~s}\left(\mathrm{FEV}_{1}\right)$ to forced vital capacity (FVC) $<0.8$ to 0.9 and $\mathrm{FEV}_{1}$ increase by $\geq 12 \%$ following bronchodilator or reliever medication is diagnostic for asthma (3). Additional criteria, such as change in forced expiratory flow between $25 \%$ and $75 \%$ of pulmonary flow $\left(\mathrm{FEF}_{25-75}\right)$, are also considered (4). In adults, this metric is variable because $\mathrm{FEF}_{25-75}$ is dependent on FVC. However, in children and young adults, there is greater elastic recoil, and $\mathrm{FEF}_{25-75}$ may be more meaningful (5). Fraction of exhaled nitrous oxide (FeNO) correlates with eosinophilic inflammation in the lung and has been the subject of recent research investigation. The basis for its use as a biomarker in asthma rests on the correlation among

\section{L'association entre la fraction expirée d'oxyde nitrique, la réponse aux bronchodilatateurs et le type de corticoïdes inhalés}

\begin{abstract}
HISTORIQUE : La fraction expirée d'oxyde nitrique (FeNO) est un marqueur connu d'inflammation des voies respiratoires et a fait l'objet d'études récentes sur le contrôle de l'asthme chez les enfants.
\end{abstract}

OBJECTIF : Examiner le lien entre la FeNO et la réponse aux bronchodilatateurs mesurée par spirométrie et par les types de corticoïdes inhalés (CI).

MÉTHODOLOGIE : Sur une période d'un an, des chercheurs ont procédé à l'analyse d'enfants évalués par spirométrie et FeNO dans un centre régional d'asthme pédiatrique.

RÉSULTATS : Au total, 183 enfants ont participé à l'étude (âge moyen [ \pm ÉT] de $12,8 \pm 2,8$ ans). Le fluticasone a surtout été utilisé ( $\mathrm{n}=66$ [36,1\%]), suivi du ciclésonide $(n=50[27,3 \%])$. La plupart des enfants $(n=73[39,9 \%])$ avaient un asthme persistant modéré. Une FeNO plus élevée s'associait à un changement en pourcentage du volume expiratoire maximal par seconde (VEMS) après une bronchodilatation rajustée en fonction de la rhinite allergique, du tabagisme des parents et du type de $\mathrm{CI}(\mathrm{B}=0,08$ [95 \% IC 0,04 à 0,12$]$; $\mathrm{P}<0,001)$. De même, la FeNO s'associait à un changement en pourcentage qui se situait à un débit expiratoire maximal de $25 \%$ à $75 \%$ du volume pulmonaire $\left(\mathrm{DEM}_{25-75}\right)$ après rajustement de la bronchodilatation en fonction du tabagisme parental et du type de $\mathrm{CI}(\mathrm{B}=0,13$ [95 \% IC 0,01 à $0,24] ; \mathrm{P}=0,03)$. La FeNO représentait seulement $16 \%$ et $9 \%$ de la variabilité de la VEMS et du DEM $25-75$, respectivement. La FeNO moyenne rajustée la plus basse s'observait chez les utilisateurs de fluticasone par rapport à l'absence de CI (différence moyenne de 18,6 parties par milliard [ppb] [95\% IC 1,0 à 36,2]) et il n'y avait pas de différence dans le taux de FeNO rajustée entre la prise de ciclésonide et l'absence de CI (5,9 ppb [95 \% IC $-9,0$ à 20,8]).

CONCLUSION : Les taux de FeNO étaient corrélés avec la réponse aux bronchodilatateurs dans un centre régional d'asthme pédiatrique. Cependant, la FeNO ne représentait que $16 \%$ et $9 \%$ de la variabilité de la VEMS et du $\mathrm{DEM}_{25-75}$, respectivement. La FeNO moyenne rajustée variait selon le type de CI, ce qui laisse supposer une différence d'efficacité relative entre les CI au-delà des équivalents par dose.

airway hyper-responsiveness, bronchodilator response, asthma symptoms and sputum eosinophil count (6). Importantly, there was insufficient evidence to recommend routine titration of inhaled corticosteroid (ICS) dose according to FeNO level in children over usual care, which includes spirometry (7). However, the marketing and availability of these relatively inexpensive devices to measure FeNO concentration led our clinic to investigate the relationship between traditional parameters of asthma control and FeNO across the range of ICS commonly encountered.

The objective of our retrospective review was to investigate the relationship between FeNO and bronchodilator response as measured by spirometry in a regional pediatric asthma centre. A secondary objective was to investigate the correlation between type of ICS and FeNO concentration, while correcting for equivalent dosing and known confounders.

\section{METHODS}

A retrospective chart review was conducted over a one-year period between June 2012 and June 2013. Children ( $<18$ years of age) who

\footnotetext{
${ }^{1}$ Department of General Paediatrics, The Hospital for Sick Children, University of Toronto, Toronto; ${ }^{2}$ Paediatric Asthma Centre, Orillia Soldiers'

Memorial Hospital, Orillia; ${ }^{3}$ Division of Respiratory Medicine, The Hospital for Sick Children, University of Toronto, Toronto, Ontario

Correspondence: Dr W Gary Smith, 17 Dunedin Street, Orillia, Ontario L3V 5T3. Telephone 705-327-9131, e-mail wgsmith@osmh.on.ca
} 
TABLE 1

Low, medium and high daily doses of inhaled corticosteroids in micrograms per day*

\begin{tabular}{|c|c|c|c|c|c|c|}
\hline \multirow[b]{2}{*}{ Inhaled corticosteroid } & \multicolumn{3}{|c|}{ Children 6 to 11 years of age } & \multicolumn{3}{|c|}{ Adolescents $>11$ years of age } \\
\hline & Low & Medium & High & Low & Medium & High \\
\hline Fluticasone propionate (hydrofluoroalkane propellant) & $\leq 200$ & $201-500$ & $>500$ & $\leq 250$ & $251-500$ & $>500$ \\
\hline Ciclesonide (hydrofluoroalkane propellant) & $\leq 200$ & $201-400$ & $>400$ & $\leq 200$ & $201-400$ & $>400$ \\
\hline Beclomethasone dipropionate (hydrofluoroalkane propellant) & $\leq 200$ & $201-400$ & $>400$ & $\leq 250$ & $251-500$ & $>500$ \\
\hline Budesonide (dry powder inhaler) & $\leq 400$ & $401-800$ & $>800$ & $\leq 400$ & $401-800$ & $>800$ \\
\hline Beclomethasone dipropionate (chlorofluorocarbon propellant) ${ }^{\dagger}$ & $\leq 200$ & $201-400$ & $>400$ & $\leq 500$ & 501-1000 & $>1000$ \\
\hline
\end{tabular}

${ }^{*}$ Adapted from the Canadian Thoracic Society guidelines (3); ${ }^{\dagger}$ Obtained from Global Initiative on Asthma guidelines (1) and included for comparison with older literature

\section{TABLE 2} Baseline demographic and clinical data obtained from
children in a regional pediatric asthma clinic

\begin{tabular}{lc}
\hline Demographic & \\
\hline Age, years & $12.8 \pm 2.76$ \\
Weight, kg & $53.1 \pm 23.3$ \\
Height, cm & $152.0 \pm 18.0$ \\
Height ${ }^{\star}, \%$ according to age & $55.4 \pm 29.5$ \\
Male sex & $105(57.4)$ \\
Caucasian $^{\dagger}$ & $171(93.4$ \\
FEV $_{1}, \%$ predicted & $98.2 \pm 14.0$ \\
FEV $_{1}, \%$ postbronchodilator change & $6.1 \pm 6.1$ \\
Inhaled corticosteroid dose duration, months Oral steroid in past three months $_{\text {Use of leukotriene receptor antagonist }}$ & $25.6 \pm 31.6$ \\
Eczema & $11(6.0)$ \\
Allergic rhinitis & $41(22.4)$ \\
Upper respiratory tract infection at time of testing & $61(33.3)$ \\
Parental smoking & $71(38.8)$ \\
Testing performed in spring & $9(4.9)$ \\
\hline
\end{tabular}

Data presented as mean $\pm S D$ or $n(\%) ;{ }^{*} A s$ calculated on the WHO growth curves (8); ${ }^{\dagger}$ Missing data ( $\left.n=1\right) ; F E V_{1}$ Forced expiratory volume in $1 \mathrm{~s}$

were seen in the level 2 regional pediatric asthma centre and underwent spirometry testing in addition to FeNO testing were included. This included children diagnosed with asthma on a course of ICS, as well as new referrals to the clinic who may have been prescribed ICS by their referring physician. The present study was approved by the ethics mechanism at Orillia Soldiers' Memorial Hospital, Orillia, Ontario.

\section{Data acquisition}

Data were extracted and recorded on a preconstructed standardized form. Collected data included demographic information such as age, sex, weight, height (plotted on the WHO growth curves for children [8]) and self-identified ethnic background. Clinical data included type and dose of ICS, use of a combination product (long-acting betaagonist with ICS), duration of current ICS dose, use of oral steroids in the past three months and use of a leukotriene receptor antagonist. Literature-defined confounding factors were also obtained including presence or absence of eczema, allergic rhinitis, upper respiratory tract infection at time of testing and exposure to parental smoking. The time of day and season of testing were also recorded.

\section{Spirometry and FeNO testing}

Both spirometry and FeNO testing were conducted according to American Thoracic Society (ATS) standards (9). FeNO was performed using an asthma inflammation monitor (NIOX MINO, Aerocrine, Sweden), expressed as parts per billion (ppb). Spirometry was performed using a spirometer (Koko, PDS Instrumentation, USA) and was completed after FeNO testing in all cases. Results included both pre- and postbronchodilator values of $\mathrm{FEV}_{1}$ and $\mathrm{FEF}_{25-75}$, along with percentage change. In all cases, the bronchodilator used was salbutamol $400 \mu \mathrm{g}$ following ATS standards for bronchodilator testing (10). Bronchodilator was delivered by metered-dose inhaler with an aerochamber fitted for appropriate size. The peak expiratory flow $(\mathrm{PEF})$ and $\mathrm{FEV}_{1}$ to FVC ratio were also recorded.

\section{Asthma severity and dose equivalence}

Asthma severity was determined by information from the chart using Global Initiative for Asthma (GINA) criteria (1). This information is recorded at every asthma clinic visit by either the pediatrician or the certified asthma educator. ICS dose was stratified according to low, medium and high dose according to Canadian Thoracic Society (CTS) standards (3). Dose equivalents are not available for children $<6$ years of age; therefore, the equivalent doses for six to 11 years of age were used (Table 1).

\section{Statistical analysis}

Data were entered into SPSS version 21.0 (IBM Corporation, USA) and verified for errors. Demographic and clinical data are presented as number and percentage, or mean $\pm \mathrm{SD}$, as appropriate. Model coefficients are presented with their $95 \%$ CIs, in which the coefficient B represents the expected change in $\mathrm{FeNO}$ for each unit change in the predictor variable.

The primary planned analysis was to determine the association between $\mathrm{FeNO}$ and postbronchodilation change in $\mathrm{FEV}_{1}$ by stepwise linear regression while adjusting for known confounders and demographic data. Covariates were retained in the model if they remained significant at $\mathrm{P}<0.1$. A second stepwise linear regression was performed to determine the association between $\mathrm{FeNO}$ and postbronchodilation change in $\mathrm{FEF}_{25-75}$. In both models, chosen confounders met observed constraints such as having $>10$ subjects per variable investigated (11). A third analysis, using a generalized linear model, was conducted to evaluate FeNO according to ICS type, while correcting for equivalent dose and other covariates that were found to be statistically significant. Covariates were added to the model if found to have a statistically significant difference in mean FeNO. The Bonferroni correction was used for multiple comparisons. In all final analyses, $\mathrm{P}<0.05$ was considered to be statistically significant.

\section{RESULTS}

One hundred eighty-three children were included in the study period. Baseline demographic data are summarized in Table 2. Fluticasone was used most commonly $(n=66[36.1 \%])$, followed by ciclesonide $(n=50$ [27.3\%]) (Figure 1). Most children $(n=73$ [39.9\%])had moderate-persistent asthma (Figure 2).

Increased FeNO level was associated with percent change in $\mathrm{FEV}_{1}$ adjusted for allergic rhinitis, parental smoking and ICS type $(\mathrm{B}=0.08$ [95\% CI 0.04 to 0.12]; $\mathrm{P}<0.001)$. Similarly, FeNO was associated with percent change in $\mathrm{FEF}_{25-75}$ adjusted for parental smoking and ICS type ( $\mathrm{B}=0.13$ [95\% CI 0.01 to 0.24$] ; \mathrm{P}=0.03)$. However, FeNO accounted for only $16 \%$ and $9 \%$ of the variability in $\mathrm{FEV}_{1}$ and $\mathrm{FEF}_{25-75}$, respectively.

FeNO concentration varied according to ICS type (Figure 3). Interestingly, this relationship held when the values were corrected for equivalent dose, allergic rhinitis and weight. Mean-adjusted FeNO was lowest in fluticasone users compared with no ICS (mean 


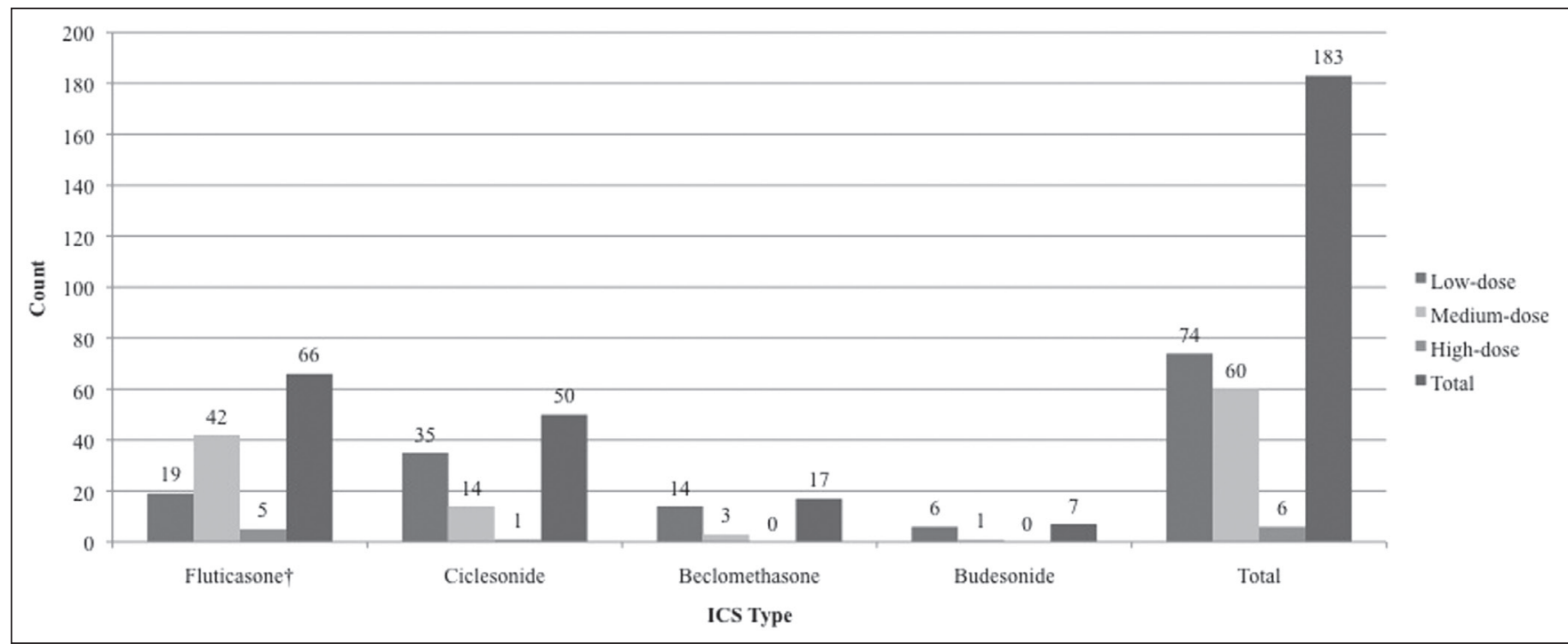

Figure 1) Distribution of inhaled corticosteroid (ICS) dose according to type of steroid among children in the pediatric asthma centre ( $n=43$ children not on ICS; ${ }^{\dagger} n=2$ children on combination product of salmerterol and fluticasone, and were included in the fluticasone group)

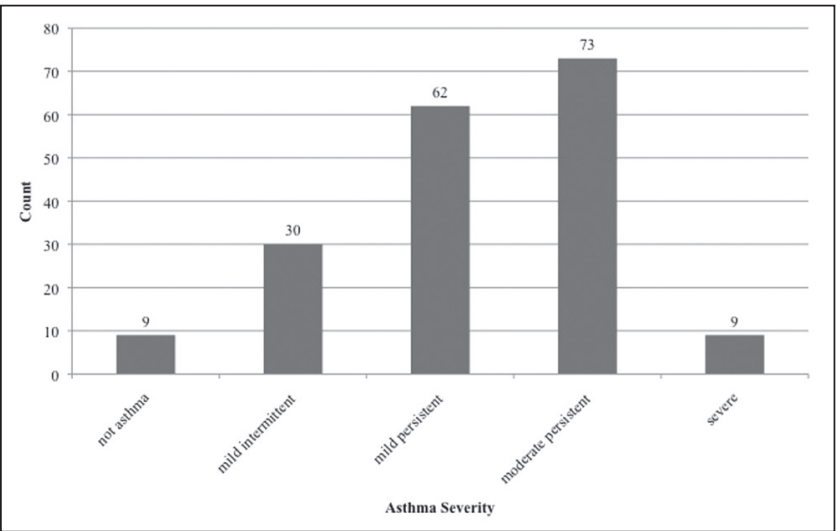

Figure 2) Distribution of asthma severity, as defined by Global Initiative for Asthma standards, at a regional pediatric asthma clinic

difference $18.6 \mathrm{ppb}$ [95\% CI $1.0 \mathrm{ppb}$ to $36.2 \mathrm{ppb}$ ]; $\mathrm{P}=0.03$ ) and there was no statistically significant difference in adjusted FeNO concentration between ciclesonide and no ICS (mean difference 5.9 ppb [95\% CI $-9.0 \mathrm{ppb}$ to $20.8 \mathrm{ppb}$; $\mathrm{P}>0.99$ ). Similarly, the comparison between both beclomethasone and budesonide with no ICS was not statistically significant (mean difference $6.6 \mathrm{ppb}$ [95\% CI -10.3 to $23.5 \mathrm{ppb}$ ] and $17.6 \mathrm{ppb}$ [95\% CI -5.0 to 40.2], respectively).

\section{DISCUSSION}

We conducted a one-year retrospective study investigating FeNO use in a regional pediatric asthma centre in children with known and suspected asthma. FeNO was associated with $\mathrm{FEV}_{1}$ and $\mathrm{FEF}_{25-75}$ response to bronchodilator, which are known parameters of asthma control. These findings confirm previous studies evaluating the association of FeNO with lung function in children with asthma $(9,12-14)$. However, FeNO only accounted for $16 \%$ and $9 \%$ of the variability in $\mathrm{FEV}_{1}$ and $\mathrm{FEF}_{25-75}$ response, respectively, indicating a high degree of variation when compared with the gold standard. This is likely due to the nonspecific nature of $\mathrm{FeNO}$ as a biomarker, which typically reflects inflammation of the airways from any cause (9). The association between FeNO and traditional parameters of asthma control forms the basis of the ATS recommendations for routine use of FeNO in titrating ICS dose in children (9). Currently, CTS guidelines differ from the ATS in this respect based on identical literature sources (7).

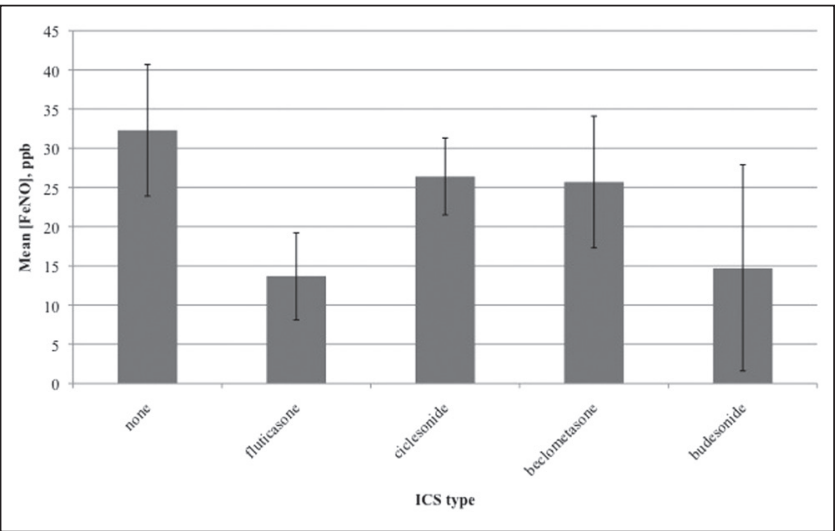

Figure 3) Mean adjusted fraction of exhaled nitrous oxide (FeNO) concentration according to inhaled corticosteroid (ICS) type. Mean values are adjusted for equivalent dose, weight and presence or absence of allergic rhinitis. ppb Parts per billion

An interesting finding was that ICS type was an important covariate when investigating the relationship between $\mathrm{FeNO}$ and spirometry results. This variable was further explored with a generalized linear model investigating the relationship between FeNO and ICS type. When correcting for equivalent dosing, FeNO levels were lowest in children receiving fluticasone, but there was no difference in FeNO level between ciclesonide and no ICS. There are several possible explanations for this finding. First, ciclesonide is a prodrug, acting locally at the site of delivery and is less bioavailable than fluticasone (15). Therefore, use of fluticasone may lead to higher basal levels of corticosteroid in situ with twice daily dosing compared with ciclesonide. Second, it could be that ciclesonide was used more predominantly in children with more severe asthma and inflammation (ie, confounding by indication); however, this association was not found in our analysis. There was also no difference between FeNO levels in children receiving beclomethasone or budesonide and no ICS; however, this result is not surprising because few children were using these medications.

Ciclesonide has been promoted due to its relatively low side effect profile, and four children with laboratory evidence of adrenal suppression recovered when switched to ciclesonide from fluticasone (16). Whether this finding is due to the relative efficacy of the drug is unknown and data measuring the overall relative potency across all ICS in children with asthma are lacking. Importantly, there are case reports 
documenting adrenal suppression in children receiving ciclesonide (17). Moreover, the most recent Cochrane Review of ciclesonide versus other ICS therapy in children with chronic asthma cautioned that equipotency may not exist, and one study comparing fluticasone with ciclesonide (2:1 ratio) found that exacerbations were more common in children receiving ciclesonide, although the grade of evidence was low (18).

Equivalent dosing studies are possible with small numbers of participants, and have been conducted in adult populations of steroid-naive patients with asthma (19). The authors used eosinophil count as a marker for inflammation to generate dose-response curves. In their study, both eosinophil count $\left(\mathrm{R}^{2}=-0.99\right)$ and FeNO $\left(\mathrm{R}^{2}=-0.97\right)$ were found to correlate with fluticasone treatment in a dose-dependent manner. A similar study involving children could be conducted; however, sputum is difficult to obtain in this population and more costly to interpret. Ciclesonide therapy has been shown to reduce FeNO within three days to two weeks of initiating $400 \mu \mathrm{g}$ of therapy in adults with asthma $(20,21)$. A similar decrease was observed after three days in adults receiving a high dose $(800 \mu \mathrm{g} /$ day $)$ compared with $400 \mu \mathrm{g} /$ day, suggesting that time to onset is equally effective based on the lower dose range (20). However, this has not been reproduced in children using FeNO.

Our study had several limitations. First, the data were retrospective and, although data are meticulously recorded in our clinic, they were collected from the medical chart and our results may be limited by the retrospective nature of the study. Second, although data regarding last oral steroid use and duration of current ICS type were obtained, we did not obtain data regarding cumulative ICS dose, which could have

\section{REFERENCES}

1. Global strategy for asthma management and prevention, global initiative for asthma (GINA). <www.ginasthma.org/documents/1> (Accessed November 8, 2014).

2. Public Health Agency of Canada. Life and breath: Respiratory disease in Canada. Ottawa; 2007. <http://phac-aspc.gc.ca/publicat/2007/ lbrdc-vsmrc/index-eng.php> (Accessed November 8, 2014).

3. Lougheed MD, Lemiere C, Dell SD, et al. Canadian Thoracic Society Asthma Management Continuum - 2010 Consensus Summary for children six years of age and over, and adults. Can Respir J 2010;17:15-24.

4. Fonseca-Guedes CHF, Cabral ALB, Martins MA. Exercise-induced bronchospasm in children: Comparison of $\mathrm{FEV}_{1}$ and $\mathrm{FEF}_{25-75 \%}$ responses. Pediatr Pulmonol 2003;36:49-54.

5. Coates AL, Graham BL, Mcfadden RG, et al. Spirometry in primary care. Can Respir J 2013;20:13-22.

6. Majid H, Kao C. Utility of exhaled nitric oxide in the diagnosis and management of asthma. Curr Opin Pulm Med 2010;16:42-7.

7. Lougheed MD, Lemiere C, Ducharme FM, et al. Canadian Thoracic Society 2012 guideline update: Diagnosis and management of asthma in preschoolers, children and adults. Can Respir J 2012;19:127-64.

8. WHO Multicentre Growth Reference Study Group. WHO Child Growth Standards based on length/height, weight and age. Acta Paediatr 2006; (Suppl 4)50:76-85.

9. Dweik RA, Boggs PB, Erzurum SC, et al. American Thoracic Society documents an official ATS clinical practice guideline: Interpretation of exhaled nitric oxide levels (FENO) for clinical applications. Am J Respir Crit Care Med 2011;184:602-15.

10. Miller MR, Hankinson J, Brusasco V, et al. Standardisation of spirometry. Eur Respir J 2005;26:319-38.

11. Altman DG. Practical Statistics for Medical Research. New York: Chapman and Hall, 1991. affected our results. Third, we did not apply a measure of adherence, but this should be considered in future prospective studies. Finally, the population sample was mixed, involving suspected asthmatic patients, including both ICS users and ICS-naive patients. This may have limited the power of our analysis, but perhaps adds to the generalizability of our findings. The inclusion of steroid-naive patients enabled a comparison of FeNO levels between ICS type and individuals not on ICS.

\section{CONCLUSION}

FeNO levels correlated with known parameters of asthma control in a regional pediatric asthma centre. However, $\mathrm{FeNO}$ accounted for only $16 \%$ and $9 \%$ of the variability in $\mathrm{FEV}_{1}$ and $\mathrm{FEF}_{25-75}$, respectively. Mean-adjusted FeNO varied according to ICS type, suggesting there was a difference in relative efficacy between ICS beyond their dose equivalents. Future studies may be designed with $\mathrm{FeNO}$ to explore the relative efficacy of ICS in children with asthma.

ACKNOWLEDGEMENTS: RWS, KD, NS and WGS contributed to study design, implementation and data collection. The statistical analysis was performed by RWS, and supervised by SD and WGS. RWS prepared the first draft of the manuscript, and all authors participated in critical revision before submission for publication. WGS was the supervising author and takes responsibility for the integrity of the data and accuracy of the analysis.

DISCLOSURES: The authors have no financial disclosures or conflicts of interest to declare.

12. Sivan Y, Gadish T, Fireman E, Soferman R. The use of exhaled nitric oxide in the diagnosis of asthma in school children. J Pediatr 2009;155:211-6.

13. Smith AD, Cowan JO, Filsell S, et al. Diagnosing asthma: Comparisons between exhaled nitric oxide measurements and conventional tests. Am J Respir Crit Care Med 2004;169:473-8.

14. Malmberg LP, Pelkonen AS, Haahtela T, Turpeinen M. Exhaled nitric oxide rather than lung function distinguishes preschool children with probable asthma. Thorax 2003;58:494-9.

15. Barnes NC. The properties of inhaled corticosteroids: Similarities and differences. Prim Care Respir J 2007;16:149-54.

16. Heller MK, Laks J, Kovesi TA, Ahmet A. Reversal of adrenal suppression with ciclesonide. J Asthma 2010;47:337-9.

17. Smith RW, Downey K, Gordon M, et al. Prevalence of hypothalamic-pituitary-adrenal axis suppression in children treated for asthma with inhaled corticosteroid. Paediatr Child Health 2012;17:e34-9.

18. Kramer S, Rottier BL, Scholten RJ, Boluyt N. Ciclesonide versus other inhaled corticosteroids for chronic asthma in children. Cochrane Database Syst Rev 2013;(2):CD010352.

19. Kelly MM, Leigh R, Jayaram L, Goldsmith CH, Parameswaran K, Hargreave FE. Eosinophilic bronchitis in asthma: A model for establishing dose-response and relative potency of inhaled corticosteroids. J Allergy Clin Immunol 2006;117:989-94.

20. Erin EM, Zacharasiewicz AS, Nicholson GC, et al. Rapid effect of inhaled ciclesonide in asthma: A randomized, placebo-controlled study. Chest 2008;134:740-5.

21. Kanniess F, Richter K, Böhme S, Jörres RA, Magnussen H. Effect of inhaled ciclesonide on airway responsiveness to inhaled AMP, the composition of induced sputum and exhaled nitric oxide in patients with mild asthma. Pulm Pharmacol Ther 2001;14:141-7. 


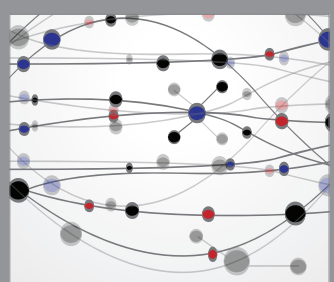

The Scientific World Journal
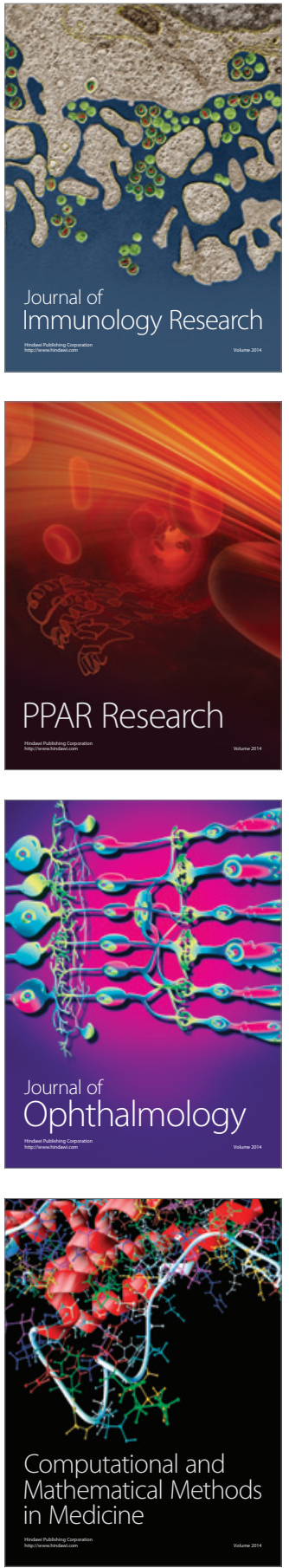

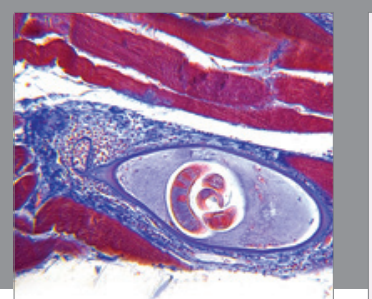

Gastroenterology Research and Practice

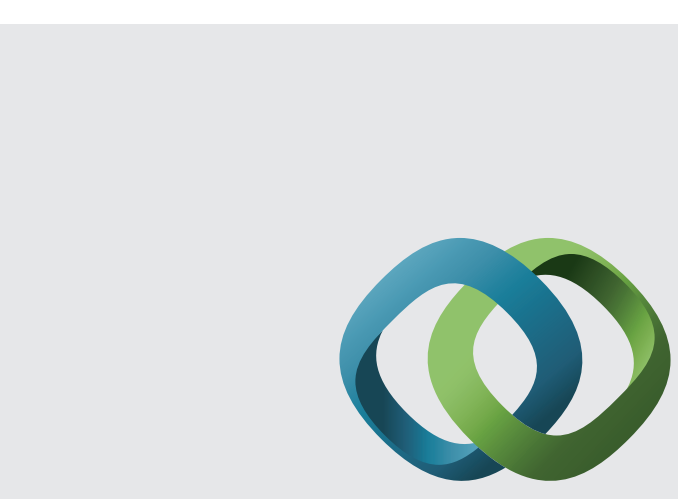

\section{Hindawi}

Submit your manuscripts at

http://www.hindawi.com
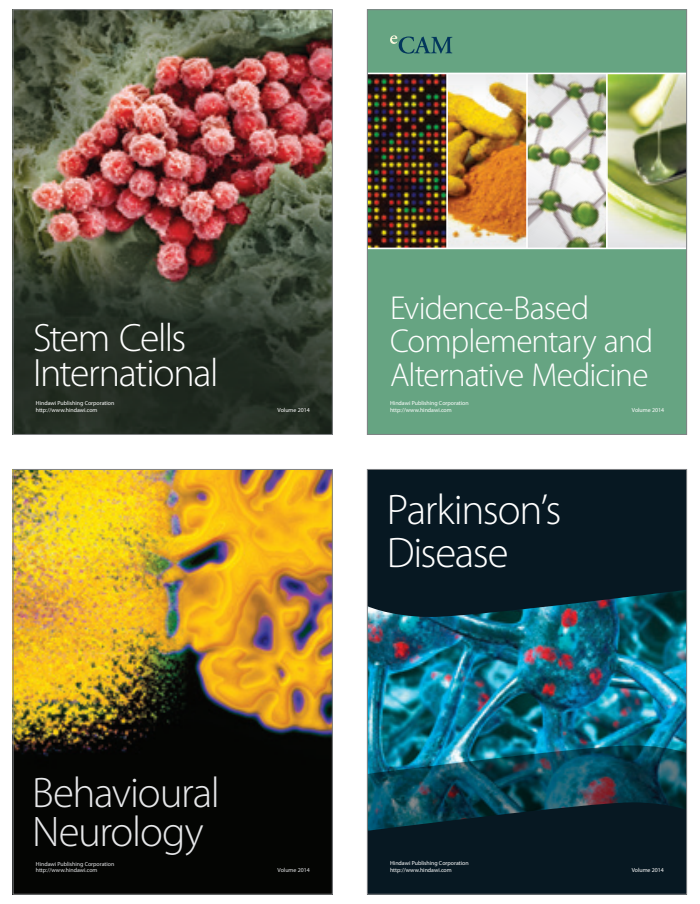
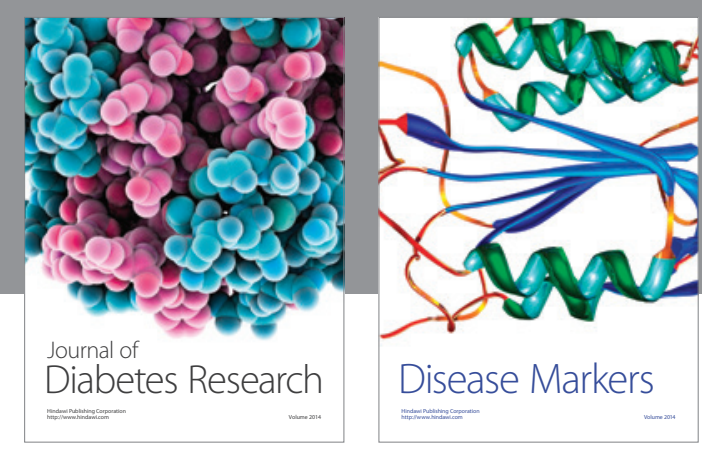

Disease Markers
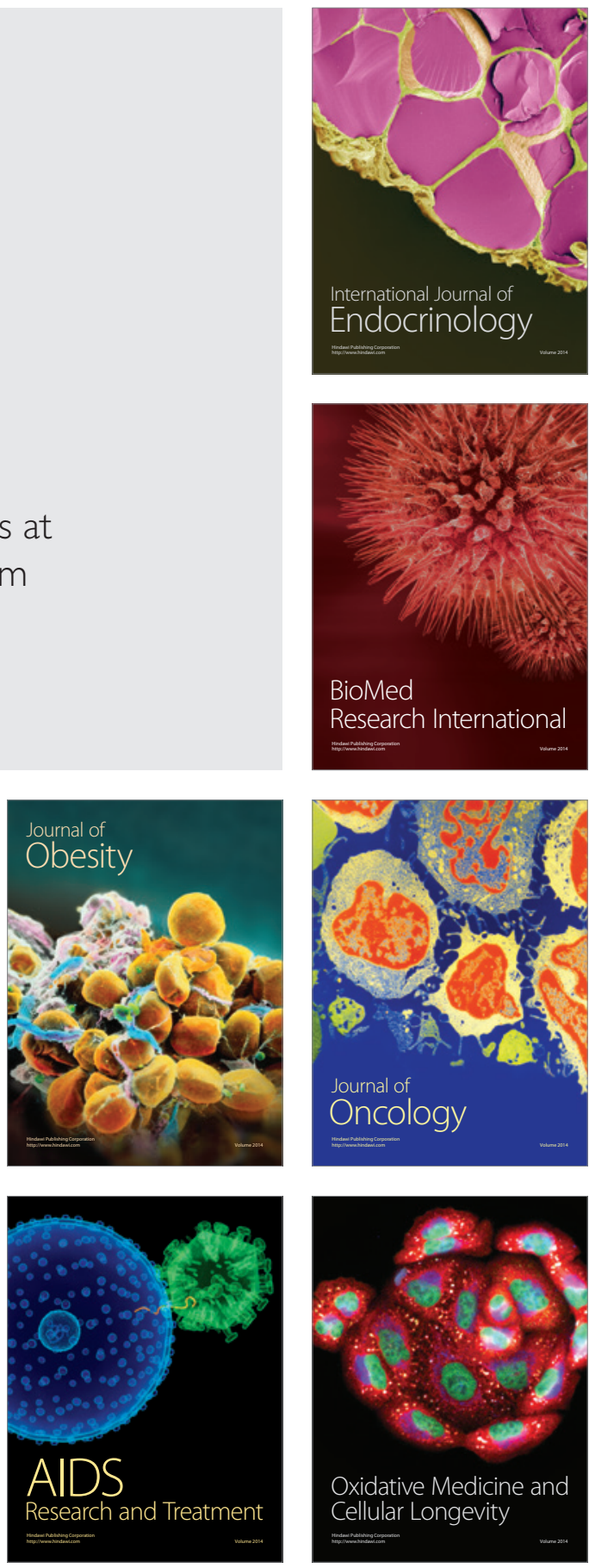